\title{
Reformation Design of the Feeding System of the Semi-Mobile Crushing Station
}

\author{
Xinyu Wang ${ }^{1, a} \quad$ Xiaoguang $Y u^{2, b}$ \\ ${ }^{1}$ School of High Vocational Technology, the University of Science and Technology Liaoning \\ ${ }^{2}$ School of Mechanical Engineering and Automation, the University of Science and Technology \\ Liaoning \\ Email:a-95764301@qq.com, b-yuxiaoguang58@163.com
}

Key words: the semi-mobile crushing station, the feeding system, reformation design

\begin{abstract}
The crusher station of the Qi Dashan mine is the semi-mobile crushing station. The crusher station has three parts. They are a heavy plate type material feeder having a receptacle trough, a crusher having a tower for controlling and a blowdown equipment. The hazard rate of the heavy plate type material feeder having a receptacle trough is hign and it operating cost is costly. So the heavy plate type material feeder having a receptacle trough will be thrown off. A new feeding system will take the place of it. And new steel structure beams will be designed. The weight of the new feeding system will be born by the steel structure beams. The ore or rock will be pured into the crusher directly.
\end{abstract}

\section{Current architecture of the semi-mobile crushing station in the Qi Dashan mine}

Two semi-mobile crushing stations are introduced from the Krupp Works of Germany in 1995. The two semi-mobile crushing stations are all under the jurisdiction of the Qi Dashan mine. One smashes the rock. And the other smashes the ore. They costed 3 hundred million RMB at that time. One semi-mobile crushing station includes three parts. As illustrated in Fig. 1. They are a heavy plate type material feeder having a receptacle trough(as illustrated in Fig. 2), a crusher having a tower for controlling and a blowdown equipment. The core of the semi-mobile crushing station is a $60 "-89$ " cratonic cycle model crusher. The driving power of the crusher is $597 \mathrm{kw}$. The production capacity of the ore is $4100 \mathrm{t} / \mathrm{h}$. The production capacity of the rock is $6100 \mathrm{t} / \mathrm{h}$. The maximal feeding materials size is $1500 \mathrm{~mm}$. The maximal discharging-material size is $50 \mathrm{~mm}$. The two semi-mobile crushing stations start to use in the beginning of the year 1997. The adaptive stage high of the heavy plate type material feeder having a receptacle trough is $12 \mathrm{~m}$. The useful volume of the receptacle trough is $615 \mathrm{t}$. The length of the material feeder is $31 \mathrm{~m}$. The lenient of the material feeder is $2.512 \mathrm{~m}$. The obliquity of the material feeder is $24.95^{\circ}$. The running speed is $0 \sim 0.5 \mathrm{~m} / \mathrm{s}$. The main generator is drived by fluid power. The main generator's power is $2 \times 400 \mathrm{kw}$. The installation power of the material feeder is $856 \mathrm{kw}$. It's gross weight is $795 \mathrm{t}$. From 1997 to now the operating cost of the heavy plate type material feeder having a receptacle trough is very high and the failure rate is also high. These cause resource-wasting largely. The semi-mobile crushing station will be transformed. The material feeder having a receptacle trough will be thrown off. The load of feeding equipment will be absorbed by the steel structure beams. The ore and the rock will be drawn into the receptacle trough directly. This will bring more economic effect.

Where 1 is the heavy plate type material feeder having a receptacle trough. 2 is the crusher having a tower for controlling. 3 is the blowdown equipment.

Direct expense cost. The power consumption of the heavy plate type material feeder having a receptacle trough is 451.2 ten-thousand-yuan every year. And it wears the cost of the scraping belt and attachment 150 ten-thousand-yuan every year. It's operating cost reaches up to 601.2 ten-thousand-yuan every year. 


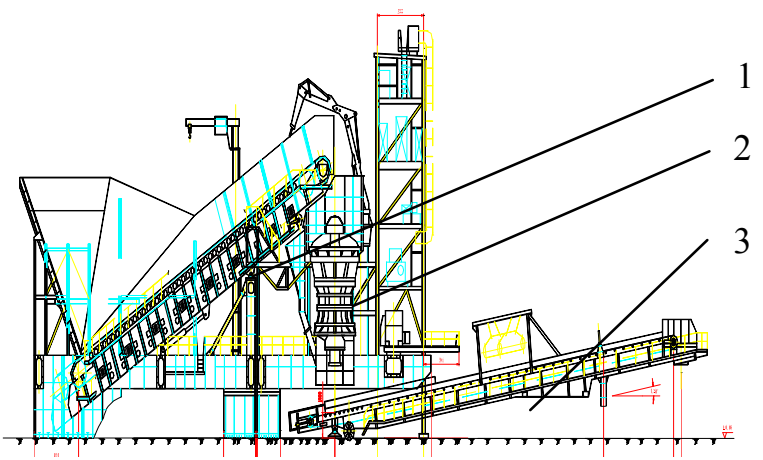

Fig. 1. The Model of Qi Dashan

Semi-mobile Crushing station

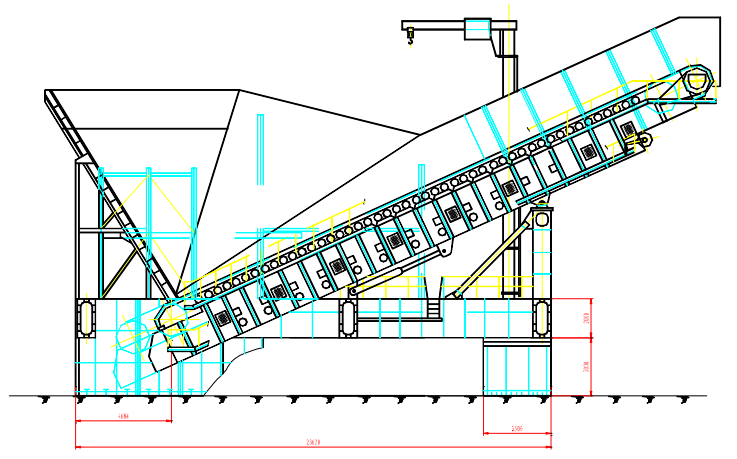

Fig. 2. The Model of Heavy Plate Type Material Feeder

Indirect expense cost. The crusher can not be filled with ore or rock using the heavy plate type material feeder having a receptacle trough. This reduces the productivity effect. This is also uneconomical operation. If the crusher can be filled with ore or rock the productivity effect will be increased. And this will reduce using scaleboard. This will save operating expense. The failure rate of the heavy plate type material feeder having a receptacle trough is very high. The replacement time of the scraping belt and the attachment is $100 \times 2$ hours. These reduce the operating rate of the system.

\section{Structure design of the steel structure beams}

The semi-mobile crushing station will be transformed. The heavy plate type material feeder having a receptacle trough will be thrown off. The steel structure beams will be designed. The weight of the new feeding system will be born by the steel structure beams. The steel structure beams are welded steel plates. They are space steel structure. The steel structure beams have two parts. One part is the main beam. The other part is the auxiliary beam. The main beam have two beams and the auxiliary beam have four beams. The structure is enormous. As illustrated in Fig. 3. The four tips of the main beam are set on the concrete shoulder. And they are welded partly. The eight tips of the auxiliary beam are fixed using bolts.

Structure of the steel structure beams. The new crushing station have two parts. They are a crusher having a tower for controlling and a blowdown equipment. The heavy plate type material feeder having a receptacle trough will be thrown off. The crusher having a tower for controlling and a blowdown equipment will parallelly move $23.82 \mathrm{~m}$ to the dumping terrace. The socket of the dumping terrace will be widen. The headroom will be $17 \mathrm{~m}$. A new receptacle trough will be set up on the top of the crusher. The steel structure beams will be around the new receptacle trough. There will be two EH3500 EV with in-wheel motor drives on the steel structure beams. The two EH3500 EV with in-wheel motor drives will take off ore or rock to the new receptacle trough. The new receptacle trough will be syndeton in block. Finishing the installation and the backout will take $3 \sim$ 5 days. And the moving of the crusher having a tower for controlling and a blowdown equipment will not be influenced. The weight of the new receptacle trough is $650 \mathrm{t}$. And the gross weight of the new feeding system will be born by the steel structure beams.

The plan view of the semi-mobile crushing station after reformation is as illustrated in Fig.3, where 1 are the main beams. 2 are the auxiliary beams. 3 is the receptacle trough.

The throat of new receptacle trough for ore after reformation is $140 \mathrm{~mm}$. And the throat of new receptacle trough for rock after reformation is $180 \mathrm{~mm}$. The crusher can be filled with ore or rock using the new feeding system. The output will be stable. The output of the ore will be $4000 \mathrm{t} / \mathrm{h}$. The output of the rock will be $6000 \mathrm{t} / \mathrm{h}$. The maximal discharging-material size of ore is $300 \mathrm{~mm}$ before reformation. The maximal discharging-material size is $230 \mathrm{~mm}$ when the throat is $140 \mathrm{~mm}$. The maximal discharging-material size of rock is $350 \mathrm{~mm}$ before reformation. The maximal discharging-material size is $300 \mathrm{~mm}$ when the throat is $180 \mathrm{~mm}$. These will raise the beneficiation 
capacity. These will reduce using scaleboard. This will save more operating expense. The full-scale mock-up model of one girder and the inner structure of one girder are as illustrated in Fig. 4 and in Fig.5.

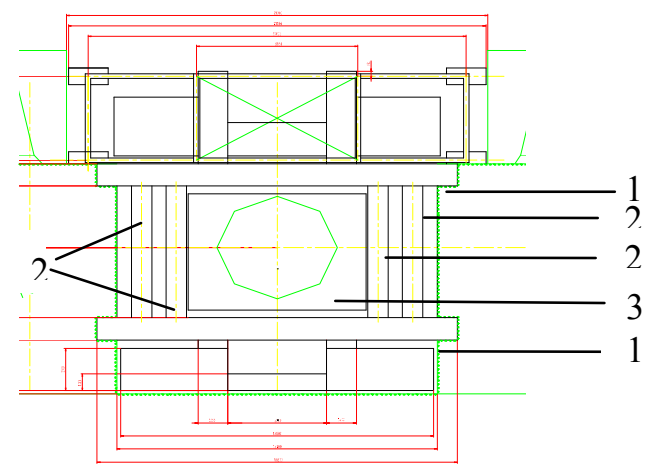

Fig. 3. The Plan View of Semi-mobile Crushing Plant after Reformation

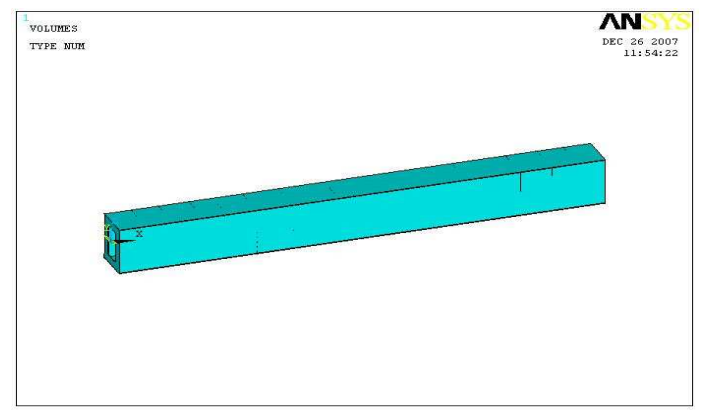

Fig. 4 .The Full-scale Mock-up Model of One Beam

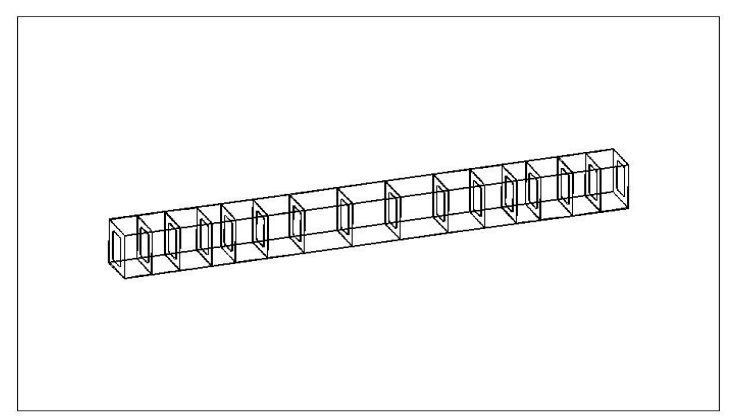

Fig. 5. The Inner Structure of One Beam

Load for the steel structure beams. There are two part loads.

(1) The autologous weight of the steel structure beams

Because $\mathrm{G}=\mathrm{mg}$ and $\mathrm{m}=\rho \mathrm{v}$ the weight of the steel structure beams can be obtained. Where $\mathrm{m}$ is the gross mass of the $16 \mathrm{Mn}$ steel plates. The $\rho$ is the density of the $16 \mathrm{Mn}$ steel plate and $\rho=7430 \mathrm{~kg} / \mathrm{m}^{3}$. The $\mathrm{v}$ is the volume of the beams. Through calculating the volume of the main beams is $2.3068 \mathrm{~m}^{3}$. If $\mathrm{g}=9.8 \mathrm{~N} / \mathrm{kg}$ we can have $\mathrm{m}=17139.5 \mathrm{~kg}$ and $\mathrm{G}=167967.3 \mathrm{~N}$.

Through calculating the volume of the auxiliary beams is $0.98314 \mathrm{~m}^{3}$. If $\mathrm{g}=9.8 \mathrm{~N} / \mathrm{kg}$ we can have $\mathrm{m}=7304.7 \mathrm{~kg}$ and $\mathrm{G}=167967.3 \mathrm{~N}$.

(2) The weigh of the carrying capacity

Two EH3500 EV with in-wheel motor drives are on the steel structure beams. The autologous weight of the two EH3500 EV with in-wheel motor drives is 140t. The maximal carrying capacity is 190t. So the gross weight is $330 \mathrm{t}$.

\section{Summary}

Using the transformed semi-mobile crushing station will reduce the cost of production immensely. And this will enhance the economic performance. The reformationed feeding syste has been tested. And it can meet the need of practice manufacture.

\section{References}

[1] Xinyu Wang ,the Finite Element Analysis and the Optimization Research of the Semimobile Fracture Device.(scientific dissertation).anshan: the University of Science and Technology Liaoning,2007

[2] Chenglin Lv , the Assembly and the Shift of Semi-mobile Crushing Plant for Ore and Rock.Mineral engineering, 2003, 4, 45-49 